\title{
A Negative-Income-Tax Experiment
}

\author{
Would payments to those who earned less than a certain amount reduce \\ their incentive to work? The initial results of an unusual test with \\ 1,300 families indicate that the payments would have no such effect
}

\author{
by David N. Kershaw
}

$\mathrm{T}$ The welfare-reform proposals of both President Nixon and Senator McGovern embody the concept of the negative income tax: a downward extension of the income-tax system that would pay out cash (negative taxes) to families at the low end of the income scale. An essential feature of the concept is that as a family's income rises above the poverty level the tax payments are reduced by an amount less than the earnings, so that the family is always better off the higher its own earnings are. The concept was first presented to a broad public in 1962 by Milton Friedman of the University of Chicago, who argued that the negative income tax would strengthen the market economy and individual initiative by enabling poor people to make their own decisions on spending and saving and would cut back on the large and growing apparatus of social-welfare programs.

It is difficult to predict what the impact of a negative-income-tax plan would be on the people covered and on the economy. The word "experiment" is often applied to new social programs, but it is not used in the normal scientific sense. For the past four years, however, my colleagues and I at Mathematica Incorporated, working with a group at the Institute for Research on Poverty of the University of Wisconsin, have been conducting a more rigorous kind of social experiment to test the effects of a negative income tax. Money for the experiment was provided by the U.S. Of- fice of Economic Opportunity. The main objective of the work has been to explore the key question about the negative tax, namely the extent to which it would reduce the incentive of the recipients to work. The extent of such a work reduction will determine both the actual cost of a new program and whether or not it is acceptable to the taxpayers. Our preliminary findings indicate that a negative income tax does not significantly reduce the earnings of the recipients. We think the findings also point to the value of social experimentation as a tool for policy makers.

The need for some such technique 1 arises from the large sums that the Government regularly commits to the eradication of one social ill or another: additional housing for the poor, health facilities for the elderly, medical care for the indigent, school lunches for poor children and so on. Since the supply of skills and money for these activities is limited, the legislative process becomes essentially a system of bargaining or of trading off one set of programs for another. On what basis do Government officials recommend one set of programs rather than another? What criteria do legislators employ to measure the probable effectiveness of one idea as opposed to another? The fact is that there have been few effective ways for determining the effectiveness of a social program before it is started; indeed, in most cases it is impossible even to forecast the cost of a new social program until it has been in operation for some time.

Clearly this situation is not conducive to sound and effective decision making. Moreover, it results in such unforeseen disasters as the Medicaid scandals, empty public-housing projects and relentlessly increasing costs for welfare programs. Social experimentation of the kind I am discussing is a tool that has been developed and tested in the past five years for avoiding unanticipated developments in new social programs and for measuring in advance what the programs will cost.

What is usually unforeseen in a new program is how the people affected by it will behave. What they do, of course, is likely to have a profound effect on the program. For example, in the Medicaid program unexpectedly high fees charged by physicians and hospitals and unexpectedly high use of the services took policy makers by surprise. Various behavioral changes induced in the recipients similarly determine the cost and effectiveness of new income-transfer programs. Since most major social programs will induce changes in behavior, which in turn will affect the program, it is clearly vital for policy makers to understand the magnitude and direction of such changes in behavior in advance in order to make the most rational choices among new programs.

A social experiment as we view it has the same general design as an experiment in the natural sciences. One under- 
takes to identify the experimental population, then to change one of the variables affecting its behavior and finally to compare its subsequent behavior with that of a control population in which the variable has not been changed. If the experiment is well designed, the investigator can attribute any difference in the behavior of the experimental population to the stimulus. The question we faced was whether or not this approach would work when the population consisted of human beings, when the laboratory was the community and when the stimulus was a complex new social program.

Our experiment was the first attempt to answer the question. The experiment has been conducted as the New Jersey Negative Income Tax Experiment because its first operations were in Trenton, although it was later extended to Scranton, Pa., as well as to three other cities in New Jersey: Paterson, Passaic and Jersey City. Negative-income-tax payments were begun in Trenton in August, 1968, and were ended in Scranton last month. The only part of the experiment now in progress is the analysis of the data.

The welfare-reform proposals of the 1 two presidential candidates are among a number of negative-tax plans that have been advanced in recent years. Although the various plans differ in many ways, all of them are defined by two common variables: the guarantee level and the rate of reduction (sometimes called the tax rate) applied to the guarantee.

The guarantee is the amount paid to a family or an individual with no other income. In a negative-income-tax system the guarantee would be in effect a floor under incomes, providing a basic level of income for everyone. Various guar-

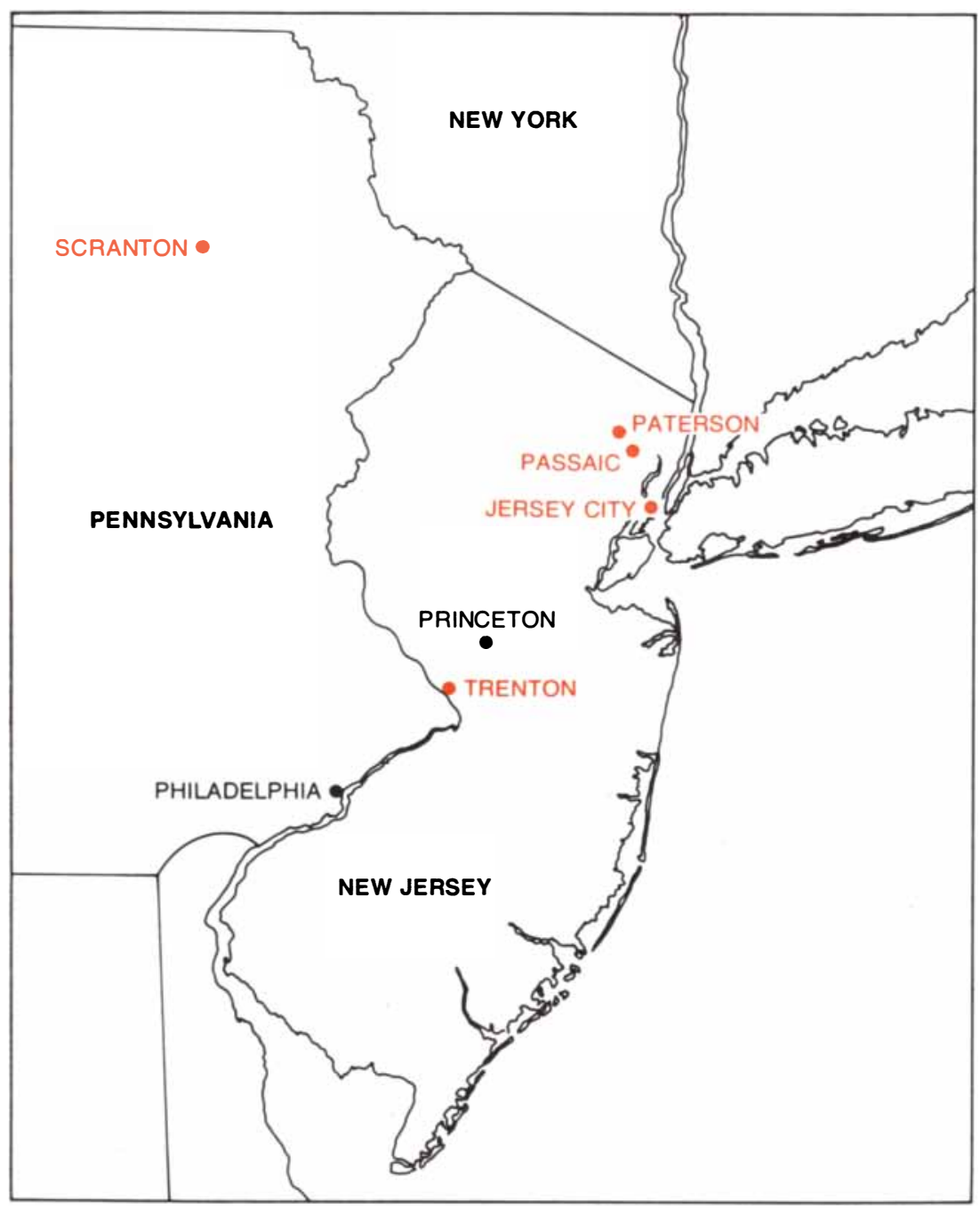

FIVE CITIES (color) where the negative-income-tax experiment was conducted were chosen from the Northeast because it is densely populated and has many working poor people. An ethnic balance was also sought. The negative-tax payments began in Trenton in 1968. antee levels have been proposed, ranging from $\$ 2,400$ annually for a family of four (the amount in H.R. 1, a House of Representatives bill incorporating the Administration's proposals for welfare reform) to $\$ 6,600$ per year (advocated by the National Welfare Rights Organization).

The rate of reduction is the rate at which the negative-tax payments are reduced as the family's other income rises. The reduction is always less than the amount of the rise in other income. That is to say, for each dollar of other income the family receives, the negative-tax payment is reduced somewhat, but not dollar for dollar. A dollar-for-dollar reduction formerly applied in welfare programs, and the rate in such programs remains high today.

The guarantee and the rate of reduction can be combined in many ways. Suppose the guarantee is $\$ 3,000$ and the rate of reduction is 50 percent [see illustration on opposite page]. A family with no earned income receives the full $\$ 3,000$, and the reduction is not applied. If in the next year the family's earned income is $\$ 1,000$, the rate of reduction of 50 percent means that the negativetax payment to the family is reduced by $\$ 500$. The family now receives $\$ 2,500$ in negative-tax payments and $\$ 1,000$ of its own income for a total of $\$ 3,500$. The reduction works just as the positive income tax works; in this example the family is effectively in a 50 percent marginal tax bracket.

The key point is that the family's total income continues to rise as its earned income rises, notwithstanding the reduction in negative-tax payments. Just as in the positive-tax program, the family is always better off with a higher earned income. The point is important because it shows that the negative-income-tax system is designed to minimize the disincentive to work that has often been associated with welfare programs. People who are able to work keep a portion of their earnings just as people in the positive-tax system do.

In the example I have given, the family would continue to receive negativetax payments until its own income reached $\$ 6,000$. At that level the family would become a taxpayer rather than a tax recipient. As long as the level remained above $\$ 6,000$ the family would receive no payments. If the income dropped below $\$ 6,000$, the payments would be resumed.

Choosing the "best" combination of guarantee level and rate of reduction is a difficult problem. The two things one is most concerned with in a welfare sys- 


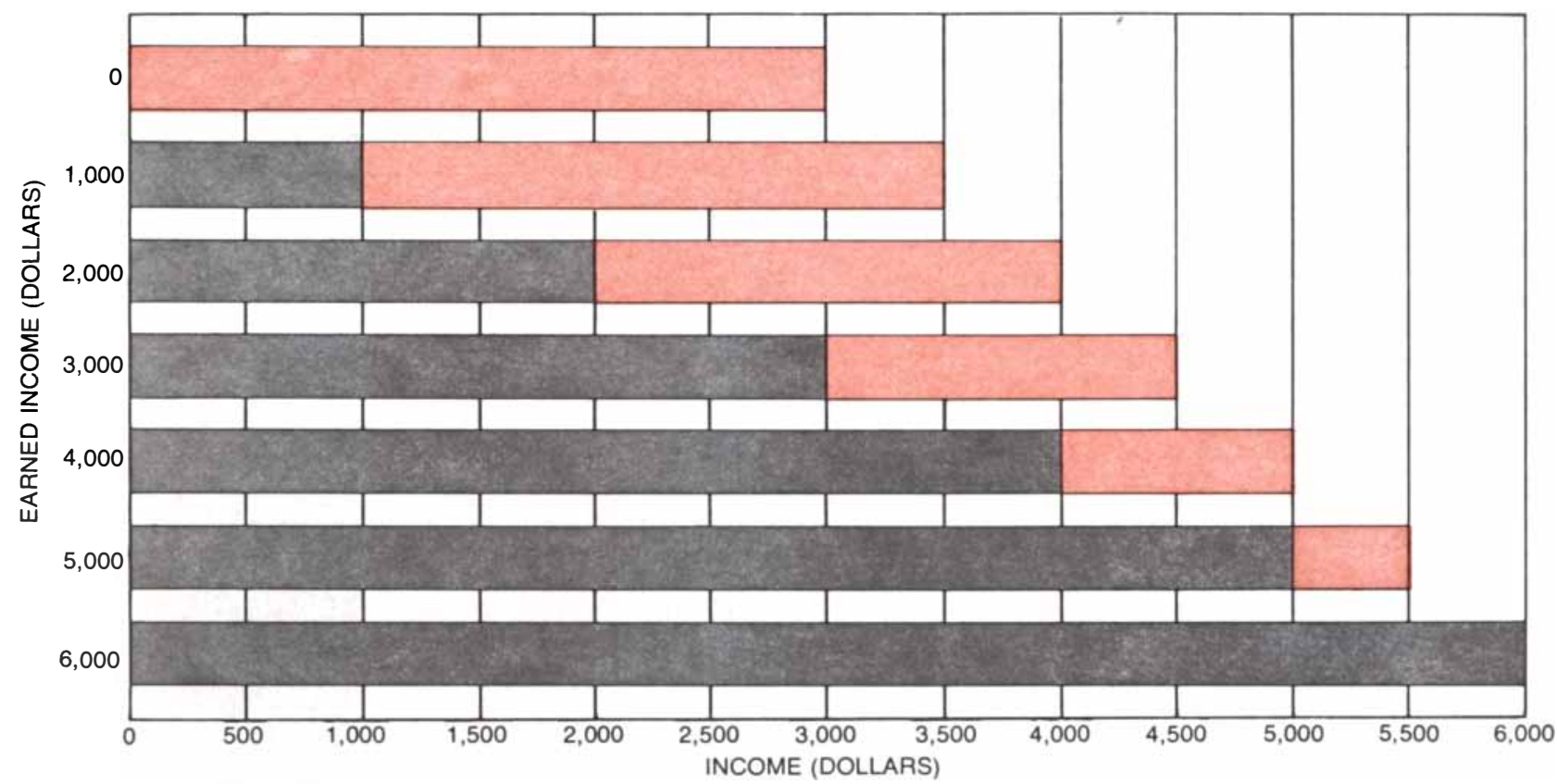

RELATION between the guarantee (color) and the earned income (gray) is charted for a guarantee of $\$ 3,000$ and a rate of reduction of 50 percent. The guarantee is the amount paid under a negativeincome-tax plan to a family with no other income; the rate of re-

duction is the rate at which negative-tax payments are reduced as other income rises. The reduction is always lower than the amount of the rise in other income, so that the recipient is always better off by having earnings than by relying solely on the negative tax.

tem are (1) how much it will cost and (2) whether or not it will have a strong tendency to make the recipients disinclined to work. Unfortunately the objectives of low cost and minimum work disincentive are in direct conflict [see illustration on next page].

The problem is evident if one envisions plans applying rates of reduction of 30,50 and 70 percent respectively to a guarantee of $\$ 3,000$. At 30 percent a family would continue to receive payments until its earned income reached $\$ 10,000$, which is close to the median income in the U.S. for a family of four. Under this plan half of the families in the nation would be recipients of negative-tax payments. Although the low rate of reduction would presumably keep the work disincentive low, the cost would be very high. On the other hand, a rate of reduction of 70 percent would keep the cost of the system down but could severely limit the incentive to work.

The problem of establishing an appropriate guarantee level and rate of reduction, of ascertaining the effect of various combinations on work behavior and of estimating the cost of a national program led to a decision by the Office of Economic Opportunity that a field experiment should be undertaken as a way of obtaining evidence. In 1967 the office gave money for the experiment to the Institute for Research on Poverty and to Mathematica, which has its head- quarters in Princeton, N.J. These organizations shared the responsibility of designing the experiment and of analyzing the data, and Mathematica set up the administrative system.

The design of the experiment was focused on the work-response issue. Given a guaranteed annual income, how much, if any, would recipients reduce their work effort? The designers of the experiment decided that the population of most interest consisted of intact families among the working poor. The work response of single-parent families and of the aged and disabled were of less interest. Data on the work response of single-parent families were partly available through the program of aid to families with dependent children, and it appeared that the cost of a guaranteed income for the aged and the disabled could be estimated without a field test since the variability of their response to negative-tax payments was limited. For these reasons the designers decided that the sample for the experiment should consist of intact families with ablebodied males between the ages of 18 and 58 who were either in the labor force or physically capable of entering it.

A second major decision concerned the method of choosing the participants. The designers considered a national sample, which would consist of families chosen on a random basis from places in every region of the country; a "saturation" experiment, consisting of all the eligible families in a given area, and a "test-boring" approach involving a limited number of families from several geographic areas. It appeared that a national sample would cost too much and would be risky administratively in view of how little was known about conducting a social experiment of this kind. The saturation approach was rejected both for its cost and because it was difficult to see how data from a single area would be helpful in making generalizations about a national negative-tax program. IVe decided on the test-boring approach.

Choosing the site involved several con4 siderations. The first decision was to concentrate on an urban area, since most of the working poor live in cities. Second, we focused on the Northeast because it is densely populated and is close to IVashington, so that the Office of Economic Opportunity could more easily participate in the decision making. In the end we settled on New Jersey because it is densely populated and has a substantial number of poor people. Moreover, the state government was interested in the experiment. Trenton was chosen as the pilot site because it is close to Princeton (and so to Mathematica) and because as the capital of New Jersey it facilitated liaison with state officials. Paterson, Passaic and Jersey City were added later because they are fairly large cities, and Scranton was added because 


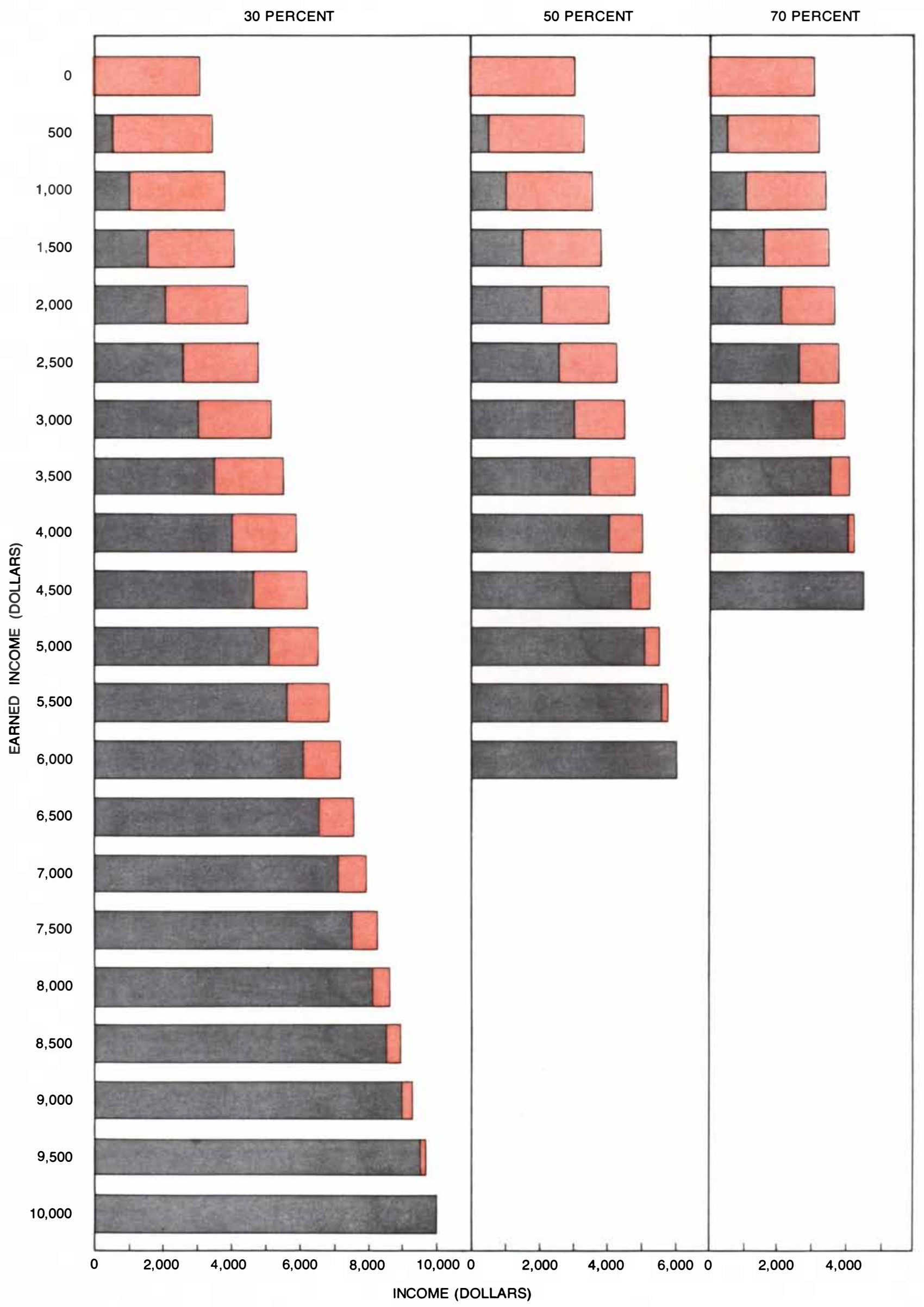


its preponderance of white residents would bring an ethnic balance to a sample that was otherwise largely black or Puerto Rican.

The selection of families was based on two preliminary interviews: a 44question screening survey administered to about 30,000 families in the five cities and a 340-question "pre-enrollment" interview administered to 2,300 families. Both interviews obtained information on the composition of the family and on income. In addition the pre-enrollment interview provided baseline measurements of certain other sociological and economic variables.

The designers decided to test three rates of reduction: 30,50 and 70 percent. The reasoning was that this group of rates covered the relevant policy range, inasmuch as a national program would never be designed with a reduction rate lower than 30 percent (on cost grounds) or higher than 70 percent (on work-disincentive grounds). Four guarantee levels were established, ranging from $\$ 1,650$ (half of the official poverty level for a family of four in 1967) to $\$ 4,125$ (125 percent of the poverty level). Eight combinations of reduction rate and guarantee level were established, and each one was designated as a "plan" [see illustration on this page].

More than 1,300 families have been involved in the program, although some have dropped out and are not reflected in our data. Somewhat more than half of the 1,300 families were assigned to one or another of the eight negative-tax plans. The other families constituted a control group that received no negativetax payments, although they were interviewed periodically just as the experimental families were. A control group is necessary in order to be able to compare the families receiving payments with families of similar situation who are not. In this way the experimenter can be sure that random events in the cities are not responsible for the results he is measuring.

In order to participate in the experiment the families in the group receiving payments were required only to report their correct income and any changes in family composition. The reports, which we verified through various auditing procedures, were made every four weeks to the Council for Grants to Families, a

\begin{tabular}{|c|c|c|c|}
\hline F POVERTY LINE & 30 PERCENT & 50 PERCENT & 70 PERCENT \\
\hline \multirow{2}{*}{\multicolumn{4}{|c|}{$\begin{array}{c}\$ 1,650 \\
50 \text { PERCENT }\end{array}$}} \\
\hline & & & \\
\hline \multicolumn{4}{|l|}{$\$ 2,475$} \\
\hline \multicolumn{4}{|l|}{75 PERCENT } \\
\hline \multicolumn{4}{|l|}{$\$ 3,300$} \\
\hline \multicolumn{4}{|l|}{100 PERCENT } \\
\hline \multicolumn{4}{|l|}{$\$ 4,125$} \\
\hline 125 PERCENT & & & \\
\hline
\end{tabular}

EIGHT COMBINATIONS of guarantee and rate of reduction employed in the negative-tax experiment are indicated by the colored squares. The "poverty line" was established in 1967, when the negative-tax experiment was designed, as $\$ 3,300$ per year for a family of four. corporate body set up by Mathematica and the Institute for Research on Poverty to process and disburse payments. On the basis of income reported to the council, families were paid every two weeks by check sent by mail from Princeton. The council also had an office in each of the experimental cities to answer questions from the families and from Princeton.

Families were free to do whatever they wished with the payments. They also could move anywhere in the U.S. If a member left the original family unit, he or she still received a share of the family grant. Payments were excluded from taxable income under a ruling obtained from the Internal Revenue Service.

Tn addition to the income data on the 1 forms mailed in by the experimental families every four weeks, information on the work response and other characteristics of the sample was obtained from interviews administered every three months by the Urban Opinion Surveys Division of Mathematica to both the experimental and the control families. The questionnaires sought information on such matters as participation in the labor force, financial status, medical and educational histories, family structure and political and social integration. Twelve such interviews were made, and a 13th quarterly interview was under-
GUARANTEES AND REDUCTIONS are shown on the opposite page in various combinations. For each level of earned income the negative-tax payment (color) and the earned income (gray) are indicated for three rates of reduction. The problem in arriving at an optimum combination is that a low rate of reduction results in a costly negative-income-tax plan and a high rate tends to make the recipients less inclined to work to increase income. taken to ascertain what understanding the families had of the experiment.

We have now obtained a great deal of information about the 1,300 families. We shall be analyzing the results for another year. Unanalyzed portions of the data will be made available, under controlled conditions, to investigators over the next few years. Even though the analysis is not complete, we have reached a stage where it is possible to describe the principal results in a preliminary way.

The most important results, of course, are those that bear on the work response. The question to be asked here is: How did the work behavior of the families in the experimental group compare with the work behavior of the families in the control group? The preliminary results give no evidence indicating a significant decline in weekly earnings as a result of the introduction of the payments [see illustration on page 25]. About 31 percent of the families in the experimental group showed earning increases of more than \$25 per week, compared with about 33 percent of the controls. About 25 percent of the experimental families showed earning declines of more than $\$ 25$ per week, compared with 23 percent of the controls. These differences are too small to be regarded as statistically significant. That is a most encouraging finding.

A second finding in terms of work response was identified when improvements in the computer system enabled us to analyze indicators other than earnings. One such indicator was the number of hours worked. An analysis primarily made by Harold Watts of the University of Wisconsin, who is the principal inves- 


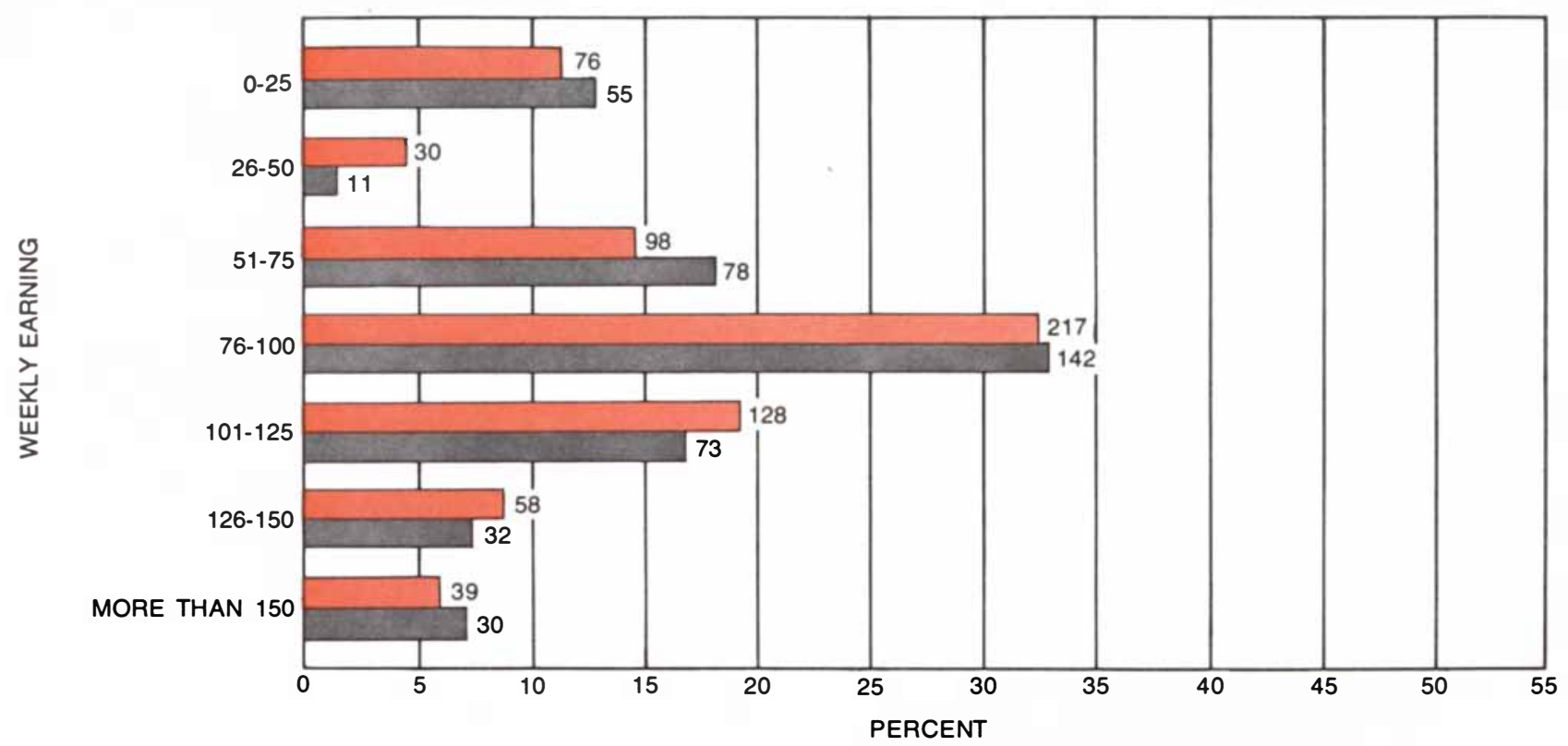

WEEKLY EARNINGS of the families that received negative-tax payments (color) are compared with the weekly earnings of the "control" families (gray) at the beginning of the experiment. The control families received no payments but were treated otherwise in the same way as the families receiving negative-tax payments. Numeral at end of each bar shows number of families in the group.

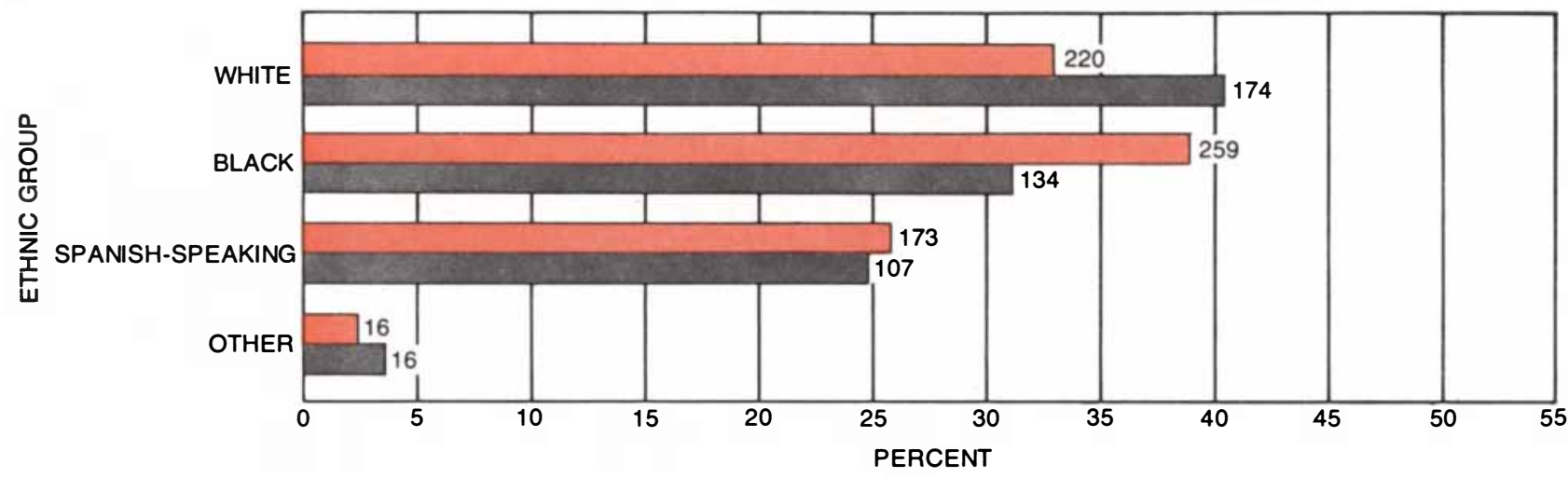

ETHNIC DISTRIBUTION of the families in the experiment is indicated. The colored bars represent families that received negative- tax payments and the gray bars the control families. Until Scranton was added, most of the sample was either black or Puerto Rican.

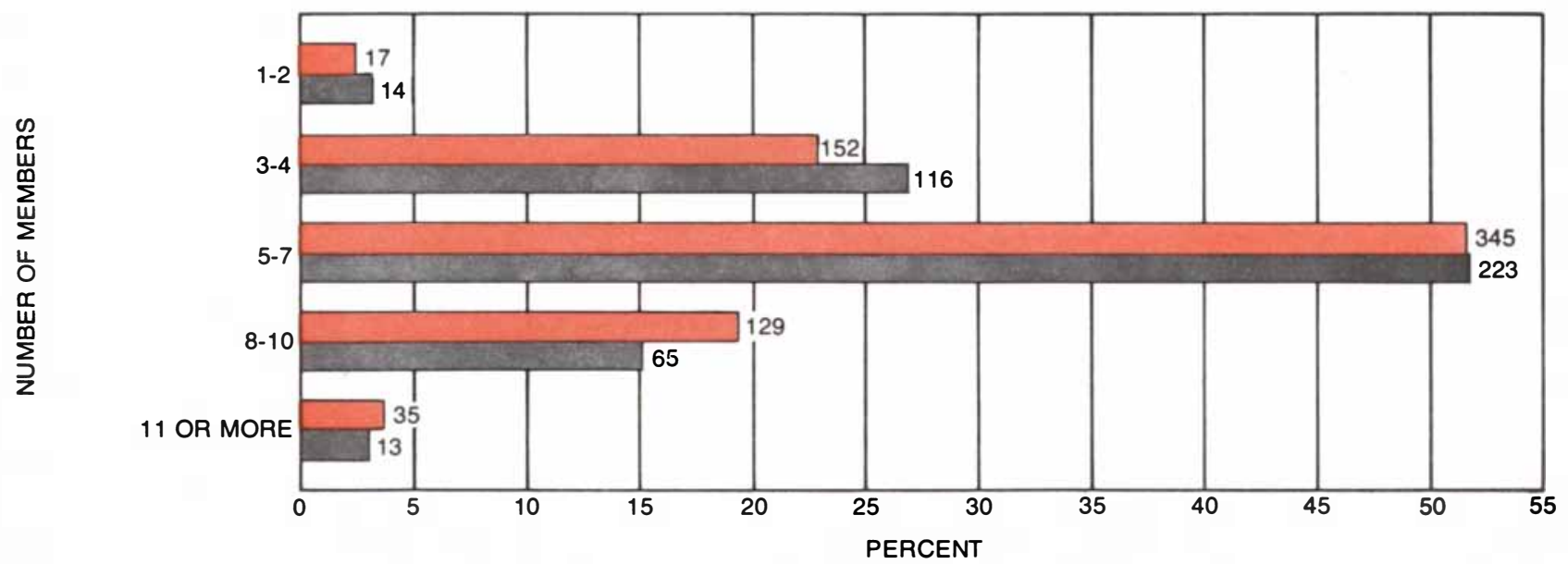

FAMILY SIZE of participating families is charted. Again the colored bars represent families that received payments, the gray bars represent control families and the numerals give the number of families in each group. A member of a family who left the household after the beginning of the experiment continued to receive his or her proportionate share of the family's negative-tax payment. 
tigator in the experiment, showed that the hours worked by families in the experimental group are about 12 percent fewer than the hours worked by families in the control group. The difference is statistically significant.

Close examination reveals that about 40 percent of the difference is attributable to primary earners in the experimental group who worked less than primary earners in the control group. The reasons appear to be small differences in overtime pay, in periods of unemployment and in time spent on a second job. The remaining 60 percent is attributable to spouses and other adult workers in the family. Interestingly enough, it does not appear that these people are leaving the labor force in comparison to the control group; instead it seems that they are entering the labor force less rapidly. This observation suggests that the reason for the lower number of hours worked in the experimental group may be that people in those families take longer to look for better jobs. The availability of the negative-income-tax payment enables the worker to do that instead of having to accept the first job he finds.

The possibility that recipients spend more time looking for better jobs is a hypothesis; it may not be the actual reason for the reduction in hours worked. Attributing precise causes is a complicated process. Further analysis may provide answers. In any case a reduction of only 12 percent suggests that the introduction of a national negative-income-tax program will not give rise to a tidal wave of voluntary idleness. It certainly would be encouraging if people are reducing their work hours in order to look for better jobs.

W e have also obtained information on the attitudes of the people in our experimental and control populations toward work. There would appear to be little reason for low-income workers to adhere to the "Protestant ethic." Why should they consider work a good thing? In the labor market they have met discrimination, low wages, poor working conditions and arbitrary layoffs. For some reason, however, the people we interviewed generally supported the idea of work. This attitude could prove significant if the nation undertakes to develop an income-maintenance system that provides a smooth transition from poverty to reasonable affluence.

It is conceivable that the most important and lasting result of the New Jersey experiment will be the support it pro-

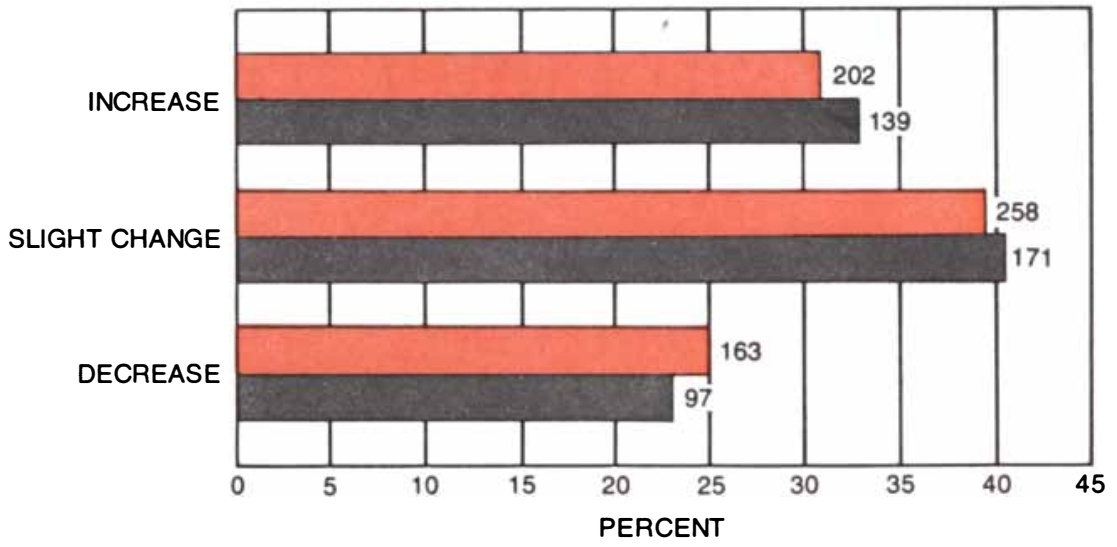

CHANGE OF EARNINGS of families that received negative-tax payments (color) and of control families (gray) is charted for the first two years of the experiment. "Increase" means a rise of more than $\$ 25$ per week, "slight change" a rise or fall of less than $\$ 25$ and "decrease" a decline of more than $\$ 25$. Since the comparisons are so close, there is no statistically valid evidence that the payments curbed the recipients' incentive to work.

vides for the idea of social experimentation. Although the experiment encountered a number of serious unforeseen problems, in general it worked: families were chosen and assigned to experimental or control groups, money was paid, interviews were conducted, data were assembled, analysis was done and results were sent to Washington, where policy makers used them. A more rigorous question is whether social experimentation is a cost-effective way of obtaining answers to policy questions.

The weaknesses of the method are fairly clear: it is an expensive way of gathering information (the cost of the New Jersey experiment will be almost $\$ 10$ million in the end); it takes a long time to get results, since measuring human behavior with confidence requires at least several years, and it is difficult to control the environment of the experiment. The strengths of social experimentation as a policy tool are also rather clear: it is the only way to obtain information on some kinds of behavioral change before a new program is introduced; it is the best way to collect precise information on specific issues because it is carefully structured and controlled, and it can help to focus the attention of able and imaginative scholars and professionals on new issues. On balance, social experimentation has thus far proved to be an effective new tool.

The he New Jersey experiment has given rise to, or at least encouraged, a number of other social experiments. The rural negative-income-tax experiment, sponsored by the Office of Economic Opportunity and conducted by the Institute for Research on Poverty, covers
800 rural families in Iowa and North Carolina. The Department of Health, Education, and Welfare has provided money for income-maintenance experiments in Seattle, Gary, Ind., and Denver and also for the Vermont family-assistance-planning study, which was designed to explore the more important administrative issues in the Family Assistance Plan. The experiments in housing allowance, sponsored by the Department of Housing and Urban Development, give housing vouchers to poor families in several cities with the aim of studying the response of families and landlords, the demand and supply of housing and how a national housingallowance program might be administered. The Office of Economic Opportunity is sponsoring an education-voucher demonstration and a health-insurance experiment. The education-voucher program seeks to measure the effect on communities and students of giving all parents in a particular area vouchers good for education at a school of their choice. In the health-insurance experiment about 2,000 families will be placed on various health-insurance plans to measure how the utilization of medical services changes in response to differences in the cost of medical care.

Other social experiments are under consideration. They involve such issues as child care, problems of income measurement and administrative techniques in cash-assistance programs. One can anticipate that an increasing number of policy decisions on major social programs will be made with the assistance of information obtained through social experiments undertaken to explore these issues and others yet unforeseen. 